\title{
AnÁlise dos Serviços ReCEBidos pelos Alunos de Pós-Graduação da Faculdade de Odontologia de Piracicaba - UNICAMP
}

Roberto Almada Leitão

Mestre em Administração - FGN/Unimep.

Administrador de Empresas - Unimep

Coordenador do curso de Administração com ênfase em Marketing - Faculdades Hoyler/ Hortolândia

Antônio Carlos Giuliani

Administrador, Mestre e Doutor em Educação pela UNIMEP Coordenador e professor do Curso de Mestrado

Profissional em Administração

giuliani.marketing@uol.com.br

Nadia Kassouf Pizzinatto

Administradora e economista- UNIMEP. Doutora, Mestre e Especialista em Administração - EAESP/FGV

Professora de Cursos de Mestrado da UNIMEP.

nkp@merconet.com.br

João Sarmento Pereira Neto

Mestre/Doutor em Ortodontia e Ortopedia Facial FOP/Unicamp

Faculdade de Odontologia de Piracicaba - UNICAMP

Professor Dr. Assistente da área de Ortodontia da FOP/Unicamp

Especialista em Radiologia Oral - UERJ

\section{RESUMO}

\section{ABSTRACT}

Este trabalho teve por objetivo verificar a satisfação dos alunos quanto aos serviços oferecidos pelo programa de Pós-Graduação em Ortodontia da FOP-UNICAMP, de modo que os resultados coletados e analisados forneçam subsídios para o Planejamento de Marketing da IES. Como instrumento de coleta de dados foi utilizado questionário baseado no modelo SERVQUAL, composto por 36 sentenças, que focalizam a percepção e a expectativa do aluno em relação à qualidade dos serviços recebidos. A amostra foi composta pelos alunos do Programa de Pós-Graduação da área de Ortodontia. A qualidade dos professores e a qualidade das disciplinas têm um maior grau de relevância para a qualidade do curso. Com base nos questionários respondidos, observou-se que os alunos percebem que a qualidade dos docentes é fundamental para a satisfação em um curso de Pós-Graduação, mas que há deficiência nesse aspecto.

Palavras-chave: Planejamento de marketing, marketing serviços, Instituições de Ensino Superior.
The objective of this paper is to verify the satisfaction of students regarding the services offered by a graduate program in Orthodontics of the FOP-UNICAMP (College of Dentistry - University of Campinas, Piracicaba City, São Paulo State) in order to collect and analyze data to support the IES Marketing Planning. A questionnaire based on SERVQUAL model, composed of 36 sentences, that focused on the perception and the expectation of the students regarding the quality of the received services was used as instrument for collecting data. The sample was composed of students in the Graduate Program of the Orthodontics area. The quality of the professors and the quality of the subjects have a greater degree of relevance in the quality of the course. Based on the answered questionnaires, it was observed that the students perceived that the quality of the professors is basic to the satisfaction in a graduate course. However, it was discovered that deficiency in this aspect still exists.

Key words: Marketing Planning, 


\section{INTRODUÇÃO}

Na última década a educação superior brasileira sofreu intensas mudanças, especialmente a Pós-Graduação (PG) stricto sensu. Hoje, a Pós-Graduação é um elo importante na constituição das diversas relações que promovem o desenvolvimento tecnológico e científico do país, por meio da interação e parcerias com os sistemas econômico, social e cultural; assim, vem contribuindo para a formação de profissionais e professores para os diversos níveis da economia e educação, prestando serviços comunitários em regiões carentes de desenvolvimento estrutural, criando parcerias interinstitucionais e, até, interagindo com empresas para a transferência de conhecimento em setores estratégicos, como o de tecnologia.

É importante compreender que a grande demanda pelos cursos de graduação, que surgiu nos últimos anos, também reflete quantitativa e qualitativamente na demanda dos programas de Pós-Graduação, que são os principais formadores de docentes e pesquisadores para as novas instituições e cursos de terceiro grau que proliferam no país. Segundo dados do INEP (2003), as matrículas no ensino superior do setor público passaram de $800 \mathrm{mil}$ em 1997 para 1 milhão em 2002. No setor privado, o registro foi de 1,2 milhões em 1997, passando para 2,4 milhões em 2002, apresentando um crescimento de $100 \%$ de matriculados nas instituições privadas. Enquanto o número de IES (Instituições de Ensino Superior) no setor público, em 1980, era de 200 instituições (aumentando para 208 instituições em 2003), no setor privado, no mesmo ano, havia 682 instituições, que aumentaram para 1.752 em 2003.

O rápido crescimento e a forte expansão do sistema universitário, em nível de terceiro grau, no Brasil ocorrem, principalmente, por iniciativa do setor privado. Esse processo de expansão tem sido tão forte que tem motivado acirrada concorrência entre muitos mantenedores da educação superior. Macedo (2002, p. 28-32) afirmou que, em 2000, as instituições privadas eram responsáveis por $67 \%$ das ofertas de matrícula, ficando as públicas com $33 \%$. Esta situação não é a mesma no ensino de PósGraduação, onde os maiores investimentos são feitos pelas IES públicas.

As IES passam, hoje, por um processo complexo de transformações, mas devido às suas singularidades, IES públicas requerem capacidades administrativas ajustáveis à própria realidade. Para Heerdt (2002, p. 01), as mudanças no ambiente educacional têm levado muitas organizações a adotar uma renovação do modelo de gestão, com o qual a universidade busca inovar na prestação de seus serviços, sendo o objetivo principal satisfazer com qualidade as necessidades de alunos-clientes cada vez mais exigentes.

Sobre a importância desse processo, Rodrigues (2003, p. 10-11) afirma que o ensino superior deve ter um papel importante e desafiador na construção e desenvolvimento de uma nova cultura e sociedade na qual está inserido, junto com a evolução científica, tecnológica e de inovação. $\mathrm{O}$ esforço para trazer para junto da sociedade a realidade da Universidade Pública, com suas atividades, as dificuldades do seu cotidiano, os objetivos e todo o grande processo que a constitui, deve ser um compromisso daqueles que fazem parte dos segmentos que a compõem, principalmente dos gestores de diversos níveis em IES.

As técnicas de marketing utilizadas em IES estão baseadas no entendimento (avaliação) dos diversos problemas de mercado (interferências externas), no qual o foco principal é criar estratégias para a satisfação dos seus públicos. O marketing deve ser uma atividade central na busca do atendimento das necessidades daqueles que fazem parte do processo como alunos, professores, doadores e a sociedade em geral.

Para Kotler e Fox (1994, p. 28) devem-se atender as necessidades de longo prazo do consumidor principal, que é o aluno, inclusive aquelas que ainda não são percebidas, como o domínio das informações e as habilidades adquiridas no processo educacional. A instituição deve, ainda, estabelecer padrões que assegurem o atendimento mais amplo da sociedade, preparando pessoas que produzam e assumam responsabilidades sociais.

O marketing educacional em instituições públicas tem o propósito de atrair e manter seus alunos através do gerenciamento da qualidade dos serviços, conseguir recursos extra orçamentários que supram as necessidades de desenvolvimento da instituição (em organismos de pesquisa e fomento) e divulgação de seus produtos e serviços para a comunidade.

A Pós-Graduação de uma IES pública é um serviço de relevante importância para o desenvolvimento da sociedade brasileira e um de seus deveres é dar especial atenção ao gerenciamento de seus serviços e recursos. Outra preocupação deve ser mostrar essa importância aos seus diversos públicos, tanto pela atuação na comunidade, como pela comunicação eficaz de seus valores e atributos.

Uma IES que se orienta pelo marketing, concentrase em satisfazer as necessidades e interesses de longo prazo de seus públicos pela eficiência e qualidade de seus programas e serviços. Entre outros compromissos com a instituição, a função da administração é posicionar sua imagem perante a sociedade criando e comunicando seus valores e atributos para os diversos segmentos alvo. Isso, segundo Kotler e Fox (1994, p. 18), pode ser resolvido porque a orientação para o marketing "força uma escola a mostrar o que está tentando fazer como instituição e quais desejos pretendem atender".

A formulação da missão e o estabelecimento de objetivos tanto em uma instituição, como em organizações empresariais, devem passar por constantes reavaliações. A condição sine qua non é a satisfação das 
expectativas pessoais da comunidade universitária. Como o comportamento esperado é a alteração das expectativas devido às fases do ciclo de consumo, as estratégias e os programas devem ser alinhados às realidades a certo momento no tempo. O suporte das informações mensuráveis é importante para o processo de tomada de decisão, pois o torna menos subjetivo, permitindo a adequação da situação à realidade da organização, podendo valorizar ações que se preocupam com os serviços pré e pós-venda, inovando, minimizando custos e adaptando-se ao ambiente (ROCHA, 2000, p. 12).

A utilização do marketing educacional extrapola a contribuição de análise e propostas de ações para o composto de serviços, permitindo, assim, solucionar possíveis problemas de adequação ao foco. Para que os programas das IES possam se diferenciar, as informações colhidas na análise são fundamentais para a comunicação eficaz quando se deseja adotar uma estratégia de posicionamento. Provavelmente muitas instituições utilizam ferramentas de marketing, mas não são orientadas para este. É tarefa dos administradores de IES determinar as necessidades e desejos, adaptarem as competências e realizar projetos apropriados, posicionando assim, as ofertas de serviços (FORTES, 2001, p. 13).

O objetivo do estudo foi verificar a satisfação dos alunos quanto aos serviços oferecidos pelo programa de Pós-Graduação em Ortodontia da FOP-UNICAMP, com base nas cinco dimensões da qualidade propostos por Parasuraman, Zeithamel e Berry ( 1985 e 1988) buscando identificar focos de insatisfação para subsidiar o Planejamento de Marketing da IES.

\section{METODOLOGIA}

Pretende-se mostrar como uma IES com orientação para o marketing pode satisfazer as necessidades a longo prazo, pela eficiência e qualidade de seus programas e serviços.

Como subsídios para identificação da qualidade foram avaliados diferentes características dos serviços oferecidos pelo Programa de Pós-Graduação stricto sensu da área de Ortodontia de uma IES pública, a Faculdade de Odontologia de Piracicaba, da Universidade Estadual de Campinas-SP, procurando conhecer os valores das pessoas e como percebem os principais atributos em relação aos serviços educacionais. Foi realizada uma pesquisa de natureza exploratória. Seus resultados trouxeram maiores informações sobre o assunto, desenvolvendo e esclarecendo conceitos e idéias de forma clara, com a finalidade de formular novas hipóteses para estudos futuros (GIL, 1995; MATTAR, 1996; COOPER; SCHINDLER, 2003).

O estudo classifica os alunos como consumidores, mesmo sabendo que a sua satisfação, apesar de sua importância central, pode ser difícil de ser mensurada, pois divergem entre si ao determinar quais características da escola estão relacionadas à satisfação de cada um. Responder ao mercado é, também, pesquisar as necessidades e preferências não manifestadas, procurando encontrar maneiras de melhorar seus serviços. A maioria das IES não procede ao levantamento das reais necessidades e desejos de seus alunos e nem estimula ou treina seus docentes para fazê-lo.

$\mathrm{Na}$ década de 80 , surgiram os primeiros trabalhos propondo modelos de qualidade em serviços utilizados para examinar as relações entre a qualidade do serviço, a satisfação do consumidor e as intenções de compra. Nessa linha, Grönroos, 1984; Parasuraman, Zeithamel e Berry, (1985 e 1988) estudaram formas para avaliar a expectativa e percepção dos consumidores. Já Cronin e Taylor (1992, p. 55) associam o interesse pela medida da qualidade do serviço à preocupação com a estratégia de posicionamento. Também Teas (1994, p. 132) avalia as expectativas dos consumidores como um padrão na medição da qualidade de serviço, fazendo surgir perguntas importantes a respeito das definições conceituais e operacionais alternativas sobre a qualidade percebida e a ligação entre qualidade percebida e a satisfação dos clientes. Em comum, o fato de que é um o problema é identificado por diversos pesquisadores, mostrando que a construção da qualidade de um serviço é abstrata e difícil de mensurar.

Levando o tema à área acadêmica, para verificar qualitativamente o processo pedagógico, Silva (1996, p. 01 02) propõe um Modelo de Verificação Qualitativa de Docentes (por não acreditar na consistência em modelos de avaliação discente), que envolve aspectos psicopedagógicos, sociológicos, multidisciplinares e com aspectos antropológicos. O modelo se distingue por focalizar aspectos cognitivos e instrumentais, ou as técnicas metodológico-didáticas utilizadas pelo docente. As características experimentais avaliadas são: pessoais, qualidades profissionais, relacionamento interpessoal, habilidades técnicas e de ensino e habilidades de comunicação. Um processo de avaliação não pode ser apenas formatado segundo modelos estritamente psicológicos, nem com uma visão puramente pragmática.

Segundo Farias et al. (1997, p. 01-13), a satisfação/ insatisfação do consumidor é uma resposta à pós-compra e a experiência emocional com o encontro dos serviços tem um papel importante no processo de satisfação. Os sentimentos contribuem, de alguma forma, para avaliar a satisfação. Por proposta dos autores citados, foi analisado o papel dos sentimentos/emoções no processo de satisfação de alunos em relação aos professores e cursos de um programa de MBA em uma Universidade Americana. As respostas mostraram que havia 25\% de satisfação com os professores e $14 \%$ com os cursos.

Pariseau e McDaniel (1997, p. 204), ao relatar as determinantes da qualidade de serviços em escolas de negócios na região Nordeste dos Estados Unidos, identificaram nos resultados que, na opinião dos estudantes, 
as Faculdades das duas universidades pesquisadas não tinham serviços com qualidade. Testes de Anova confirmam diferenças significativas na percepção da qualidade e os resultados sugerem que as escolas devem empreender esforços significativos para melhorar a qualidade e a satisfação de seus alunos-clientes.

Já o trabalho de Bandeira et al. (1998, p. 01-15) teve como objetivo propor um instrumento de avaliação da qualidade de cursos de Pós-Graduação e sugerir um procedimento para aprofundar os estudos de validação da escala proposta, sendo esta baseada no conceito de qualidade de serviços. Outro objetivo era diagnosticar problemas e instrumentalizar coordenadores de cursos com um questionário de identificação de pontos fortes e fracos e seleção de prioridades de melhorias. A metodologia utilizada foi a de adaptação de uma escala às peculiaridades do serviço-educação, tendo como modelo a escala SERVQUAL.

Estudos mais recentes (ENGELLAND, WORKMAN e SINGH，2000; MARKS，2000; FROEMMING, 2001; QUINTELLA, MELO; LEAL, 2001; HEERDT, 2002; DUTRA, OLIVEIRA; GOUVEIA, 2002), propõem para a comunidade acadêmica variadas formas de avaliação qualitativa de serviços institucionais de educação, sendo a maioria baseada na escala (modificada) da SERVQUAL, onde se permite uma flexibilidade em diversos assuntos e serviços. Por exemplo, ela possibilitaria estudar a qualidade dos serviços dentro de um campus universitário, determinar medidas globais de valor na avaliação de estudantes para docentes, identificar satisfação/insatisfação no encontro de serviços de IES, detectar casos de certificação ISO 9002 em cursos de Pós-Graduação e realizar análises de competências essenciais a coordenadores de cursos de IES.

Sendo assim, e de acordo com a literatura consultada, este estudo utiliza a escala SERVQUAL modificada, levando em consideração as características da instituição estudada, por ter sido exaustivamente utilizada, criticada e melhorada em 20 anos de estudos empíricos.

A escala SERVQUAL, criada por Parasuraman, Zeithamel e Berry (1985; 1988; 1991), Bandeira et al. (1998, p. 01-15) é apontada como o modelo mais indicado para verificar a qualidade em serviços. Baseia-se no princípio de que a insatisfação do cliente possa advir da existência de um gap entre expectativas de qualidade do cliente e a qualidade o serviço recebido pelo prestador de serviços. Segundo os autores, isso pode ocorrer em cinco dimensões da qualidade, definidas na A escala como:

a) tangibilidade - aparência física das instalações, equipamentos, pessoal e material de comunicação;

b) confiabilidade - capacidade de desempenhar o serviço prometido de modo confiável e com precisão;

c) presteza - disposição de ajudar os clientes e de fornecer o serviço com presteza; d) segurança - conhecimento, cortesia dos funcionários e capacidade de transmitir confiança e confiabilidade; e

e) empatia - atenção individualizada e cuidadosa que as empresas proporcionam aos clientes (BERRY; PARASURAMAN, 1992).

Associada ao modelo de qualidade, os autores elaboraram uma escala de Likert, com 22 itens e composta por questões referentes a cada uma das cinco dimensões da qualidade para medir expectativas e percepção. Embora tenha sido aplicada em empresas do setor de serviços, trata-se de uma escala padrão que, se necessário, pode sofrer adaptações (BANDEIRA et al., 1998, p. 01-15).

Boulding et al. (1993, p. 7-27) adaptaram a escala SERVQUAL para o serviço educacional, procurando atender às características do setor. São elas: responsividade (presteza) de professores, confiabilidade de professores, empatia de professores, segurança de professores e tangibilidade do serviço educacional. As características adotadas pelos autores citados podem não incorporar outras variáveis, também importantes, por estarem considerando em demasia a avaliação do serviço docente, não devendo, portanto serem consideradas na íntegra.

Para que o instrumento de avaliação tenha maior validade para se compreender a percepção dos discentes em relação aos serviços de Pós-Graduação da FOPUNICAMP, o instrumento foi adequado de modo a conter características (sentenças) que facilitassem o entendimento do avaliador.

O questionário usado neste trabalho está baseado no modelo SERVQUAL, adaptado ao serviço educacional de Bandeira et al. (1998, p. 01-15), por considerar o autor que este possui as variáveis mais adequadas para a pesquisa. Entretanto, foram feitas algumas modificações, focalizando, mais especificamente, a Pós-Graduação stricto sensu da FOP-UNICAMP. O questionário é composto por 36 sentenças, divididas em dois blocos: o primeiro bloco, quanto à percepção do aluno, e o segundo quanto à expectativa. Os alunos puderam opinar dentro de uma escala de diferencial semântico de sete pontos, de 1 (igual a totalmente insatisfatório) a 7 (igual a totalmente satisfatório); sendo que as variações de 2 a 6 não são classificadas. Há ainda, a opção $\mathrm{N}$, com função de não ter como o aluno opinar no caso de não ter experimentado o serviço categorizado na tabela.

Para cada categoria de qualidade avaliada foi dada uma nota em escala semântica de 7 pontos, que caracteriza a importância daquele item para o aluno, onde 1 é igual a menos importante e 7 é igual a mais importante. Optou-se por usar as palavras 'menos'e 'mais' para que seja aplicado um grau de importância maior ou menor para cada item, evitando assim o 'pouco' e 'muito' importante, que poderia dar a conotação de sem importância. Cabe ressaltar que todos os itens do composto de marketing de uma IES foram avaliados nas sentenças de 
cada categoria de qualidade.

Como amostra para o estudo, foi focalizada, na realidade, a população dos alunos do Programa de PósGraduação dos cursos de Mestrado e Doutorado da área de Ortodontia, tendo em vista que está na área clínica o caráter único das diversas formas de encontros dos alunos-clientes com os serviços prestados. Isso deu um maior subsídio ao entendimento das experiências observadas, o que contribuiu positivamente para as respostas dos questionários. Para avaliar a relação entre a expectativa do aluno (o esperado) e sua percepção (o recebido) do programa de Pós-Graduação, foi usada uma amostra de 17 alunos, sendo 9 de Doutorado e 8 de Mestrado.

\section{ANÁLISE E INTERPRETAÇÃO DOS DADOS}

O cruzamento dos dados foi feito descritivamente, pois o número de dados era pequeno para efetuar o teste de Qui-quadrado, adequado para correlacionar esse tipo de dados. Para testar a correlação entre a expectativa e a percepção do aluno sobre o curso, e assim de verificar o nível de satisfação percebido, foi feita uma análise de desvios dos escores médios dentro de cada categoria focalizada, segundo metodologia de Waller (1979), Spiegel (1993) e Pereira (1999), e aplicado o teste t pareado para medidas sobre o mesmo indivíduo.

$\mathrm{Na}$ Tabela 1 encontra-se a análise quantitativa - em médias, desvios padrões e desvios médios dos escores médios - da percepção da qualidade observada em relação à expectativa do aluno, dentro de cada categoria de qualidade pesquisada, e a probabilidade de significância pelo teste $\mathrm{t}$ de Student, da expectativa e percepção do aluno quanto às categorias, sem, no entanto, analisar qualitativamente cada variável constante em cada uma delas.

Tabela 1: Análise qualitativa da percepção em relação à expectativa em cada categoria

\begin{tabular}{|c|c|c|c|c|}
\hline Categorias & Expectutiva & Percepçio & Diferença & $\mathbf{P}(\mathbf{t})$ \\
\hline Qualidade dos professores & $0,06+0,24$ & $4,98+0,51$ & $-1,08$ & $<0,01$ \\
\hline Qualidade das disoiplinas & $6,20 \pm 0,10$ & $5,30 \pm 0,26$ & $-0,90$ & $<0,01 *$ \\
\hline $\begin{array}{l}\text { Qualidade dos aspectos tangi-wis } \\
\text { da itutituigâa }\end{array}$ & $6,30 \pm 0,11$ & $6,32 \pm 0,30$ & 0,02 & 0,41 \\
\hline 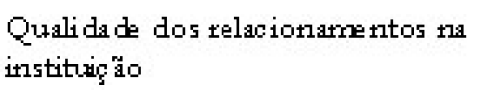 & $6,16 \pm 0,03$ & $6,02 \pm 0,27$ & $-0,14$ & 0,21 \\
\hline $\begin{array}{l}\text { Qualidade dos serwigos de apoio } \\
\text { técnico/adrnitristratiwo }\end{array}$ & $6,15 \pm 0,07$ & $5,82 \pm 0,25$ & $-0,33$ & $0,03 *$ \\
\hline
\end{tabular}

Fonte: Dados da pesquisa $\quad *$ significativo a $\mathrm{P}=1 \%$

Fica evidenciado, pela Tabela 1, que houve um impacto estatisticamente significativo e negativo da per- cepção do aluno com relação às suas expectativas sobre a categoria qualidade dos professores $(p<0,01)$, qualidade das disciplinas $(\mathrm{p}<0,01)$ e qualidade dos serviços de apoio técnico/administrativo ( $\mathrm{p}=0,03)$. Torna-se necessário identificar e interpretar os principais itens na percepção dos alunos, em cada categoria que se mostrou estatisticamente significativa e negativa. Esta análise é totalmente amparada pelos resultados apresentados nas próximas Tabelas, onde aparecem as descrições das expectativas e das percepções, bem como os cruzamentos entre as expectativas e percepções para cada questão.

Embora não significativo estatisticamente, evidenciou-se um desvio negativo da percepção em relação às expectativas na categoria qualidade dos relacionamentos na Instituição.

A categoria qualidade dos aspectos tangíveis da Instituição, embora não significativa, também merece atenção ao ser analisada porque apresentou o maior desvio positivo.

Ainda na Tabela 1, verifica-se que as médias das respostas, tanto para a mensuração do grau de expectativa quanto de percepção, apresentaram pouca variabilidade, confirmada pelo pequeno desvio padrão, demonstrando homogeneidade em todos os itens respondidos.

Com base nos questionários respondidos, os alunos percebem que a qualidade dos docentes é fundamental para a satisfação em um curso de Pós-Graduação, mas percebem, também, que há deficiência nesse aspecto, como ficou evidenciado alguns itens dos dados cruzados entre expectativa e percepção. Docente com alto grau de qualificação não garante o domínio de diversos assuntos ou que consiga estabelecer uma relação com alunos que certifique a transmissão do conhecimento de uma forma clara e objetiva, portanto, faz-se necessário que os gestores (coordenadores) de cursos observem com atenção esta variável no planejamento, garantindo a reciclagem técnica de uma forma processual e gradual, também para o domínio metodológico de aulas.

De acordo com os dados cruzados entre expectativa e percepção, no que concerne à categoria qualidade das disciplinas teóricas e práticas notouse que os itens nos quais os alunos mais esperavam obter 
qualidade eram utilidade das disciplinas para a capacitação profissional e distribuição das disciplinas durante o curso, com $100 \%$ de expectativa alta. Os dois itens apresentam o mesmo grau gerador de discordância na qualidade com expectativa alta $(100 \%) \mathrm{e}$ percepção baixa $(17,64 \%)$ e ainda os menores índices de percepção alta $(47,18 \%)$, portanto, em ambos é negativa a percepção com relação às outras variáveis nessa categoria. Se a expectativa gerada é de consenso de todos os alunos, esta deve ser vista pelo Programa como sendo de maior importância, devendo os resultados relativos à percepção totalmente satisfatória chegar bem próximos, também, da totalidade.

Os alunos esperam que as disciplinas forneçam subsídios para uma alta capacitação profissional, podendo, assim, gerar retorno sobre os custos incorridos durante o transcorrer do curso. A capacitação pode ser um diferencial no mercado de trabalho, portanto, a qualidade e distribuição das disciplinas devem ser ranqueadas, no processo de planejamento de marketing da IES, como um dos principais atributos de um programa, tendo alta prioridade na realização das expectativas dos alunos.

O planejamento de marketing permi-
10

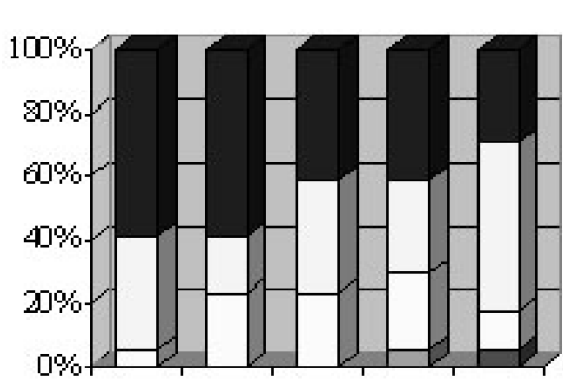

\begin{tabular}{|c|}
\hline 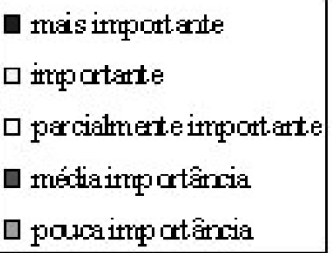 \\
\hline
\end{tabular}

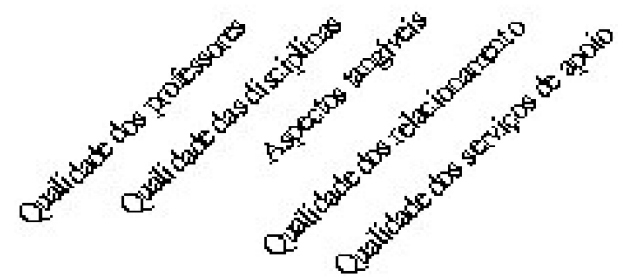

Gráfico 1: Análise descritiva do grau de importância das categorias de qualidade

Fonte: Elaborado pelos autores te o ajuste dos pontos fortes e fracos de um serviço. Sendo baixa a qualidade percebida nos serviços prestados pela equipe e se é política da universidade a não contratação de novos servidores, é preciso criar, no planejamento, procedimentos eficazes de treinamento e filosofia de marketing interno (para gerar satisfação na equipe). Esta é uma alternativa para sanar o problema, que recebe forte interferência de variáveis que são incontroláveis para os gestores de cursos.

A FOP-UNICAMP pode ser considerada uma instituição que é muito auxiliada por órgãos de fomento (como CAPES e FAPESP) através de recursos extra-orçamentários e isso se deve ao seu reconhecimento como um centro de pesquisa com relevância internacional. Uma outra fonte de recursos está nos cursos da Fundação de Desenvolvimento da UNICAMP (FUNCAMP), oferecidos pela Escola de Extensão (EXTECAMP), onde a área de Ortodontia possui em 3 diferentes cursos: especialização (Lato Sensu), atualização e de extensão (com média de 30 horas). Todos esses recursos são aplicados na própria área - já descontados os percentuais de imposto e da universidade - em equipamentos de apoio didático, material de consumo e estrutura física.

No marketing, ter pontos positivos não significa deixar de dar atenção a essas variáveis. Quando se podem atender plenamente as expectativas, neste caso com o auxílio de recursos, o trabalho deve ser feito procurando a constante superação do que se espera em termos de qualidade para o aluno. Se o serviço educacional é de difícil avaliação pelo seu aspecto intangível, é função da IES tornar os pontos que podem ser tangibilizados em objetos de alto valor, de modo a despertarem o desejo do público, especificamente o desejo dos candidatos a alunos e dos já discentes. 
recursos pedagógicos que o auxiliem para um melhor desempenho. É possível concluir que são necessárias constantes avaliações diretas do corpo docente pelo aluno, instituição e outros observadores.

A categoria qualidade dos serviços de apoio, apesar de ser avaliada como negativa em relação à expectativa (Gráfico 1), está em último lugar no grau de importância dada pelos alunos (Gráfico 2). Quanto aos aspectos tangíveis da instituição, pode-se afirmar que tem grau de importância média (Gráfico 2) e foi a única categoria, apesar de não ser estatisticamente significativa, com impacto positivo na percepção dos alunos (Gráfico 1). Essa constatação discorda da afirmação de Bandeira et al (1998) de que, no aspecto tangível houve pouca relevância (coeficiente não significativo) na opinião dos alunos frente à qualidade de ensino, pois estes atribuem significância para as variáveis: professores, disciplinas, turma e valor (estas duas últimas não verificadas neste trabalho).

\section{CONSIDERAÇÕES FINAIS}

A administração das IES tem, entre outros objetivos, a função de posicionar a imagem da instituição perante a sociedade, criando e comunicando seus valores e atributos. O marketing educacional, como ferramenta administrativa em instituições públicas, tem o propósito de gerenciar a qualidade dos serviços prestados através da avaliação dos problemas de mercado, no qual o foco principal é criar estratégias para a satisfação dos seus públicos.

A Pós-Graduação de uma IES pública é um serviço de relevante importância para o desenvolvimento da sociedade brasileira, sendo um de seus deveres dar especial atenção ao gerenciamento de seus serviços e recursos. O planejamento de marketing é um processo que possibilita gerenciar melhor a relação com o futuro e seus públicos, viabilizando ações por meio das estratégias realizadas no presente. As IES devem focar seus esforços no planejamento estratégico de marketing para melhorar a qualidade de ensino e, assim, melhorar seu posicionamento. Por meio de uma investigação exploratória, este estudo permitiu uma análise sobre a qualidade percebida pelos alunos e seu uso para o planejamento de marketing, onde são revelados pontos fortes e fracos do processo no Programa de Pós-Graduação da FOP-UNICAMP, tendo como principal importância as adaptações de uso e de planejamento do marketing aos objetivos da área, que podem acarretar melhorias para a IES.

As considerações enumeradas a seguir são conseqüências das principais atividades propostas na pesquisa, a saber, levantar o nível de satisfação percebido pelo aluno e mostrar a importância do marketing e da ferramenta qualidade para o planejamento de uma IES:
1. Embora os alunos percebam que a qualidade dos docentes é fundamental para a satisfação em um Programa de PG, também fica evidenciado, pelos resultados, que a área de Ortodontia é a categoria que mais representa um desvio negativo entre expectativa e percepção. Além da qualidade dos professores, os alunos julgam como mais importantes (em ordem decrescente), entre as categorias de qualidade estudadas, a qualidade das disciplinas, dos aspectos tangíveis, dos relacionamentos e dos serviços de apoio;

2. O planejamento da IES justifica-se pela importância em tratar e entender a descontinuidade que ocorre no ambiente, onde planos formais ajudam a acompanhar as mudanças. Os programas de PG devem refletir sobre a utilização do instrumento planejamento em todos os seus contextos (internos e externos), sendo esse um meio para definir os objetivos e tomar as decisões estratégicas em relação aos cursos e serviços oferecidos;

3. Conhecer a qualidade dos cursos é vital para o planejamento estratégico de marketing, que se utiliza da análise de recursos para identificar seus pontos fortes e fracos, suas principais necessidades e oportunidades;

4. Um programa de PG que se orienta para o marketing, além de conhecer as expectativas e necessidades de seus públicos, deve, também, comunicar-se com os outros elementos do planejamento global da instituição, permitindo, assim, uma real implantação de ações de marketing.

\section{Limitações do estudo}

Muitos são os fatores limitantes do estudo. Um deles, refere-se ao próprio entendimento sobre o planejamento de marketing aplicado ao serviço educacional e à pouca bibliografia encontrada sobre o tema.

Mais diretamente relacionados à pesquisa, temos os fatores:

1. Limitação do tamanho da amostra;

2. Tratamento dos dados que podem acarretar problemas de interpretação;

3. Falta de conscientização do aluno como respondente.

Apesar das limitações, é lícito julgar o estudo válido, tendo em vista o seu caráter exploratório. A metodologia utilizada é apenas mais uma das várias alternativas institucionais de mensurar a qualidade de cursos de PG no Brasil; os esforços empreendidos na pesquisa permitem que a canalização das informações para uma maior reflexão da comunidade acadêmica, sendo importante o seu uso como instrumento gerencial para coordenadores de cursos. 


\section{Recomendações}

Algumas sugestões se fazem necessárias, tendo em vista a dinâmica das variáveis do atual contexto em que se encontram as IES.

- No campo da pesquisa, podem ser criados desdobramentos do trabalho, que poderão explorar mais especificamente a relação entre expectativas e percepções de grupos de qualidade ainda não vistos;

- Seria também interessante, em próximos estudos, a reformulação do instrumento de pesquisa, a aplicação em amostras maiores e a coleta de opiniões de outros públicos também envolvidos no processo e utilização de pré-testes;

- Na prática, estudos podem ser conduzidos e aplicados para gerar relevantes informações que colaborem com a gestão de programas de PG, procurando imprimir um elevado grau de eficácia nas instituições.

\section{REFERÊNCIAS}

ARMONI, A Aprender virtual, ano 3, n.6, 15.ed. Marília: nov/dez/2003.

BALDI, M. Estruturação da estrutura e cultura organizacional: um estudo na UNIJUI. Revista Eletrônica de Administração de Empresas, v. 5, n. 3, nov/1999. Disponível em: <http://read.adm.ufrgs.br/read11/artigo/artigo 4 . htm>. Acesso em: 17/12/2002.

BANDEIRA, M. L. et al. Avaliação da qualidade do ensino de pós-graduação: elementos para a construção e validação de um instrumento de pesquisa. In: ENANPAD, Anais... Foz do Iguaçu,1998. 15p.

BERRY, L. L.; PARASURAMAN, A. Prescriptions for a service quality revolution in America. Organizational Dynamics. v.20, n.4, p.5-16. New York, spring/ 1992.

BOULDING, W. et al. A dynamic process model of service quality: from expectations to behavioral intentions. Journal of Marketing Research, v 30, n.1, p.7-28. Chicago, fev/1993. BRASIL. Lei no 9.394/96 (Lei de Diretrizes e Bases). Disponível em: <http://www.mec.gov.br/home/ftp/LDB.doc>. Acesso em: 3/3/2003.

COOPER, D. R.; SCHINDLER, P. S. Métodos de pesquisa em administração. 7.ed. Porto Alegre: Bookman, 2003.

CRONIN, J. J. Jr.; TAYLOR, S. T. Mensuring service quality: a reexamination and extension. Journal of Marketing, v.56, n.3, p.55-68. Chicago, jul/1992.

DUTRA, H. F. O.; OLIVEIRA, P. A. S.; GOUVEIA, T. B. Avaliando a qualidade de serviço numa instituição de ensino superior. In: ENANPAD. Anais... Salvador, 2002.

ENGELLAND, B. T.; WORKMAN, L.; SINGH, M. Ensuring service quality for campus career services centers: a modified SERVQUAL scale. Journal of Marketing Education, v.22, n.3, p.236-245, 2000.

ESTRADA, R. J. S. Os rumos do planejamento estratégico na universidade pública: um estudo de caso na Universidade Federal de Santa Maria. Florianópolis: UFSC, 2000. (Tese de Doutorado em Engenharia de Produção).
ESTRATÉGIAS de Marketing. Ensino Superior, ano5, n.58. São Paulo, jul/2003.

FARIAS, S. A. et al. Emoções e sentimentos na resposta de satisfação dos consumidores: o caso de um programa de MBA. In: ENANPAD, Anais ... Rio das Pedras,RJ, 1997. 13p.

FORTES, C. M. Implantação de politica de marketing em instituições de ensino superior. Florianópolis: UFSC, 2001. 133 p. (Dissertação de Mestrado em Engenharia de Produção).

FROEMMING, L. M. S. Encontros de serviços em uma instituição de ensino superior. Porto Alegre, UFRGS, 2001. 284p. (Tese de Doutorado em Administração).

GARCIA, H. Marketing pela qualidade de ensino. Aprender Virtual, v.4, n 2, 17.ed., p.46. Marília, mar/abr/2004.

GIL, A. C. Métodos e técnicas de pesquisa social. São Paulo: Atlas, 1995.

GIULIANI, A. C. Marketing em um ambiente globalizado. São Paulo: Cobra, 2003.

GRÖNROOS, C. A. Service quality model and its marketing implications. European Journal of Marketing, n.4, p 36-44, 1984.

HEERDT, A. P. S. Competências essenciais dos coordenadores de curso em uma instituição de ensino superior. Florianópolis: UFSC, 2002. 133p. (Dissertação de Mestrado em Engenharia de Produção).

HERNANDEZ, J. M. C.; CALDAS, M. P. Resistência à mudança: uma revisão crítica. Revista de Administração de Empresas, v.41, n.2, São Paulo: FGV, abr/jun/2001.

KARSAKLIAN, E. Comportamento do consumidor. São Paulo: Atlas, 2000.

KOTLER, P. Administração de marketing: a edição do novo milênio. São Paulo: Prentice Hall, 2000.

KOTLER, P.; FOX, K. F. A. Marketing estratégico para instituições educacionais. São Paulo: Atlas, 1994.

LIMEIRA, T. M. V. Fundamentos de marketing. In: DIAS, S. R. (Coord.). Gestão de marketing. São Paulo: Saraiva, 2003.

LOPES, F. D. Teoria Institucional e gestão universitária uma análise do processo de avaliação institucional da Unijuí. Revista Eletrônica de Administração de Empresas. Disponível em: <http://read.adm.ufrgs.br/read12/artigo/ artigo4.htm $>$. Acesso em: 17/12/2002.

LOVELOCK, C.; WRIGHT, L. Serviços: marketing e gestão. São Paulo: Saraiva, 2001.

MACEDO, A. R. de. A globalização e o ensino superior. Ensino Superior, ano 5, n.48, p.28-32. São Paulo, 2002.

MARKS, R. B. Determinants of student evaluations of global measures of instructor and course value. Journal of Marketing Education, v.22, n.2, p.108-119. Boulder, ago/2000.

MARTINS, C. B. A formação do sistema nacional de pósgraduação. In: A Educação Superior no Brasil. Brasília: CAPES, 2002.

MATTAR, F. N. Pesquisa de Marketing: edição compacta. São Paulo: Atlas, 1996.

MENDES, G. Estratégia para a excelência administrativa. Ensino Superior, ano 4, n.47. São Paulo, 2002.

NEVES, C. E. B. A estrutura e o funcionamento do ensino superior no Brasil. In: A Educação Superior no Brasil. Brasília: CAPES, 2002. 
NICKLES, W. G.; WOOD, M. B. Marketing: relacionamentos, qualidade, valor. Rio de Janeiro: LTC, 1999.

NUNES, A. K. Avaliação institucional: exigência ou necessidade? Ensino Superior, ano 5, n.52. São Paulo, 2003.

OLIVE, A. C. Histórico da educação superior no Brasil. In: A Educaşão Superior no Brasil. Brasília: CAPES, 2002.

PARASURAMAN, A.; ZEITHAML, V. A.; BERRY, L. L. A conceptual model of service quality and its implications for future research. Journal of Marketing, [S.1], v.49, p 41-45, fall/ 1985.

SERVQUAL: a multiple-item scale for measuring consumer perceptions of service quality. Journal of Marketing, [S.1], v.64, p.12-40, spring/1988.

PARISEAU, S. E.; McDANIEL, J. R. Evalution service quality in School of business. The international journal of quality \& reliability management, v.14, n.3, 1997.

PSILLAKIS, H. M. Estratégias mercadológicas. In: DIAS, S. R. (Coord.). Gestão de marketing. São Paulo: Saraiva, 2003.

QUINTELLA, R. H.; MELO, V. P.; LEAL, R. Qualidade em serviços educacionais: o caso da certificação ISSO 9002 do Curso de Especialização em Administração da UFBA. In: ENANPAD. Anais... Campinas, 2001.

RÉVILliON, A. S. P. Cultura nacional e cultura organizacional no contexto de marketing. Revista Eletrônica de Administração de Empresas, v.10, n.1, fev/2004. Disponível em: <http://read.adm.ufrgs.br/read37rtigo/artigo4.htm>. Acesso em: 17/12/2002.

RIES, A.; TROUT, J. Positioning: the battle for your min $-20^{\text {th }}$ anniversary edition. New York: Mac Graw Hill Companies, 2001.

ROCHA, D. J. A. Desenvolvimento do Balanced Scorecard para instituições de ensino superior privadas: estudo de caso da Unidade de Negócios 4 da Universidade Gama Filho. Florianópolis: UFSC, 2000 (Dissertação de Mestrado em Engenharia de Produção).

RODRIGUES, G. M. O marketing educacional nos Estados Unidos. Ensino Superior, ano 5, n.58. São Paulo, 2003.

SANTAELLA, L. Comunicação e pesquisa: projetos para mestrado e doutorado. São Paulo: Hacker Editores, 2001.

SCHWARTZMAN, J. O financiamento do ensino superior no Brasil na década de 90. In: A educação superior no Brasil. Brasília: CAPES, 2002.

SHETH, J. N.; MITTAL, B.; NEWMAN, B. I. Comportamento do cliente: indo além do comportamento do consumidor. São Paulo: Atlas, 2001.

SILVA, J. M. Verificação da qualidade da educação: um estudo exploratório orientado para a avaliação de desempenho do processo educacional. In: ENANGRAD, Anais... v.2. Florianópolis, 1996.

SOARES, M. S. A. S. et al. A educação superior no Brasil. Brasília: CAPES, 2002.

TEAS, R. K. Expectations as a comparison in measuring service quality: as assessment of a reassessment. Journal of Marketing, v.58, n.1, p.132-139, Chicago: Editora, jan/1994.

UNIVERSIDADE ESTADUAL DE CAMPINAS. Anuário Estatístico. Campinas, UNICAMP, 2003.

UNIVERSIDADE ESTADUAL DE CAMPINAS. Coordenadoria Geral da Universidade. Planejamento Estratégi- co (PLANES), v.1-4. Campinas: UNICAMP, set/2002. UNIVERSIDADE ESTADUAL DE CAMPINAS. Faculdade de Odontologia de Piracicaba. Catálogo dos Cursos de Pós-Graduação. Piracicaba, FOP/UNICAMP, 2004.

VERGARA, S. C. Projetos e relatórios de pesquisa em administração. São Paulo: Atlas, 2000. 96p. 
